of this work, is gratefully acknowledged. E.K.B. appreciates many helpful and stimulating discussions with Professors E. M. Burgess and C. L. Liotta.

Supplementary Material Available: Tables of crystal data, data collection and refinement details, final positional and anisotropic thermal parameters for nonhydrogen atoms, final positional and isotropic thermal parameters for hydrogen atoms, interatomic distances and angles, least-squares planes, and structure factors (12 pages). Ordering information is given on any current masthead page.

\section{Photolysis of Bis(triphenylphosphine)dioxygenplatinum. Generation of Singlet Oxygen}

\author{
Arnd Vogler* and Horst Kunkely
}

\section{Institut für Anorganische Chemie D-8400 Regensburg, Federal Republic of Germany Received April 27, 1981 Revised Manuscript Received July 27, 1981}

The majority of thermal reactions of coordination compounds proceeds adiabatically. ${ }^{1}$ Only a few nonadiabatic reactions, which may be accompanied by chemiluminescence, ${ }^{3}$ have been investigated. On the contrary, all photochemical reactions of transition-metal complexes which are known so far are nonadiabatic since the products seem to be formed in electronic ground states. ${ }^{4}$ We report here our observation that the photolysis of $\left[\mathrm{P}\left(\mathrm{C}_{6}-\right.\right.$ $\left.\left.\mathrm{H}_{5}\right)_{3}\right]_{2} \mathrm{PtO}_{2}$, leading to the release of electronically excited singlet oxygen, is an adiabatic reaction.

While certain organic peroxides are well-known to release singlet oxygen photochemically, ${ }^{2 b, 7}$ the photolyses of some peroxo or dioxygen complexes of transition metals such as $\left[\left(\mathrm{NH}_{3}\right)_{4} \mathrm{Co}(\mu-\right.$ $\left.\left.\mathrm{O}_{2}\right)\left(\mu-\mathrm{NH}_{2}\right) \mathrm{Co}\left(\mathrm{NH}_{3}\right)_{4}\right]^{4+8}$ and $\left[\mathrm{Ir}(\text { diphos })_{2} \mathrm{O}_{2}\right]^{+9}$ also lead to the formation of $\mathrm{O}_{2}$ but apparently in its triplet ground state.

$\left[\mathrm{P}\left(\mathrm{C}_{6} \mathrm{H}_{5}\right)_{3}\right] \mathrm{PtO}_{2}{ }^{10}$ dissolved in organic solvents such as $\mathrm{CHCl}_{3}$ starts to absorb at about $450 \mathrm{~nm}$. The extinction increases toward shorter wavelengths (at $300 \mathrm{~nm}, \epsilon 530$ ). A maximum does not appear until a wavelength of $280 \mathrm{~nm}$ where the solvent starts to absorb. When these solutions $\left(\sim 10^{-3} \mathrm{M}\right)$ saturated with $\mathrm{O}_{2}$ were irradiated $\left(\lambda_{\text {ir }}>300 \mathrm{~nm}\right)$, the complex seemed to be almost stable. When the solutions were deaerated with $\mathrm{N}_{2}$, light absorption caused a slow decomposition, indicated by a small increase of the optical density between 450 and $300 \mathrm{~nm}$. It was assumed that $\left[\mathrm{P}\left(\mathrm{C}_{6} \mathrm{H}_{5}\right)_{3}\right]_{2} \mathrm{PtO}_{2}$ photolyzed to $\mathrm{Pt}\left[\mathrm{P}\left(\mathrm{C}_{6} \mathrm{H}_{5}\right)_{3}\right]_{2}$ and $\mathrm{O}_{2}$ in the primary photochemical step. In the presence of excess $\mathrm{O}_{2}$ the

(1) For definition and classification of adiabatic and nonadiabatic (diabatic) reactions, see ref 2 .

(2) (a) Förster, Th. Pure Appl. Chem. 1970, 24, 443. (b) Turro, N. J. "Modern Molecular Photochemistry"; Benjamin/Cummings: Menlo Park, CA, 1978; Chapter 14

(3) (a) Lyttle, F. E;; Hercules, D. M. Photochem. Photobiol. 1971, 13, 123 (b) Gafney H. D; Adamson, A. W. J. Chem. Educ. 1975, 52, 480 . (c) Bolletta, F.: Rossi, A.; Balzani, V. Inorg. Chim. Acta 1981 53, L23. (d) Vogler, A.; El-Sayed, L.; Jones, R. G.; Namnath, J.; Adamson, A. W. Inorg. Chim. Acta 1981, 53, L35.

(4) Excited-state protolysis ${ }^{5}$ and exciplex formation ${ }^{6}$ of transition-metal complexes are adiabatic photoreactions. However, these reactions do not involve substantial nuclear reorganizations and are completely reversible.

(5) (a) Giordano, P. J.; Bock, C. R.; Wrighton, M. S.; Interrante, L. V.; Williams, R. F. X. J. Am. Chem. Soc. 1977, 99, 3187. (b) Giordano, P. J.;

Bock, C. R. Wrighton, M. S. J. Am. Chem. Soc. 1978, 100, 6960.

(6) Vogler, A.; Kunkely, H. Inorg. Chem. Acta 1980, 45, L265.

(7) Schmidt, R.; Drews, W.; Brauer, H.-D. J. Am. Chem. Soc. 1980, 102, 2791

(8) Valentine, J. S.; Valentine, D. J. Am. Chem. Soc. 1971, 93, 1111.

(9) Geoffroy, G. L.; Hammond, G. S.; Gray, H. B. J. Am. Chem. Soc. $1975,97,3933$.

(10) (a) Tokahashi, S.; Sonogashira, K.; Hagihara, N. J. Chem. Soc. Jpn. 1966, 87 610. (b) Wilke, G. Schott, H. Heimbach, P. Angew. Chem Int. Ed. Engl. 1967, 6, 92. (c) Nyman, C. J.; Wymore, C. E.; Wilkinson, G. J. Chem. Soc. A 1968, 561. starting complex will be regenerated. In the absence of additional $\mathrm{O}_{2}$ this recombination seems to be accompanied by an unidentified side reaction, possibly an oxidative addition of the solvent. ${ }^{11}$ The formation of $\mathrm{Pt}\left[\mathrm{P}\left(\mathrm{C}_{6} \mathrm{H}_{5}\right)_{3}\right]_{2}$ as the primary photoproduct was confirmed by low-temperature photolysis. At $77 \mathrm{~K}$ the photolysis led to the appearance of a blue emission $\left(\lambda_{\max }=445 \mathrm{~nm}\right)$ which clearly indicated the generation of $\mathrm{Pt}\left[\mathrm{P}\left(\mathrm{C}_{6} \mathrm{H}_{5}\right)_{3}\right]_{2}{ }^{12}$ The emission intensity increased with irradiation time.

Finally, it was of significance to see whether the photoreleased $\mathrm{O}_{2}$ was formed in its triplet ground state or an excited singlet state. For the detection of ${ }^{1} \mathrm{O}_{2}$ we selected 2,2,6,6-tetramethylpiperidine (TMP). It scavenges ${ }^{1} \mathrm{O}_{2}$ with the formation of a stable nitroxide radical which is easily detectable by ESR spectroscopy at room temperature. ${ }^{13}$ The particular advantage of TMP which can be utilized for application in photoreactions is that it does not absorb light at wavelengths longer than $280 \mathrm{~nm}$. In addition, it was shown that the efficiency of ${ }^{1} \mathrm{O}_{2}$ quenching by TMP derivatives is not very high $\left(k_{\mathrm{q}} \sim 10^{5} \mathrm{M}^{-1} \mathrm{~s}^{-1}\right) .{ }^{13 e, 14,15}$ Consequently, the addition of a nonreactive quencher for ${ }^{1} \mathrm{O}_{2}$ such as the widely used $\mathrm{Dabco}^{14}$ (1,4-diazabicyclo[2.2.2] octane) with $k_{\mathrm{q}} \sim 2.4 \times 10^{7} \mathrm{M}^{-1} \mathrm{~s}^{-1}$ should effectively suppress the formation of the nitroxide radical. Such a competition experiment should serve as a further proof for the formation of ${ }^{1} \mathrm{O}_{2}$.

Upon addition of TMP $\left(2 \times 10^{-3} \mathrm{M}\right)$ to a solution of $\left[\mathrm{P}\left(\mathrm{C}_{6^{-}}\right.\right.$ $\left.\left.\mathrm{H}_{5}\right)_{3}\right]_{2} \mathrm{PtO}_{2}\left(2 \times 10^{-3} \mathrm{M}\right)$ in $\mathrm{CHCl}_{3}$ saturated with $\mathrm{N}_{2}$, the absorption spectrum of the complex did not change, indicating the absence of a thermal reaction. Upon irradiation (light source: Osram $100 \mathrm{~W} / 2$ high-pressure mercury arc; cut-off filter: 310 $\mathrm{nm}$ ) the extinction of the solution increased between 500 and 300 $\mathrm{nm}$. Simultaneously a strong ESR signal $(g=2.0059$, hyperfine coupling $16.15 \mathrm{G}$ ) developed which is characteristic for the nitroxide radical of TMP formed by the reaction of TMP with ${ }^{1} \mathrm{O}_{2}{ }^{13}$ This experiment was repeated with Dabco $\left(3 \times 10^{-3} \mathrm{M}\right)$ added to the solution. ${ }^{16}$ The ESR signal now was very weak since Dabco apparently intercepted ${ }^{1} \mathrm{O}_{2}$.

The formation of ${ }^{1} \mathrm{O}_{2}$ was confirmed by an additional independent test with 1.3-diphenylisobenzofurane (DIF) as a trap for ${ }^{1} \mathrm{O}_{2}{ }^{17}$ DIF scavenges ${ }^{1} \mathrm{O}_{2}$ with high efficiency $\left(k_{1}=8 \times 10^{8} \mathrm{M}^{-1}\right.$ $\mathrm{s}^{-1}$ ). Since DIF is somewhat light sensitive, ${ }^{7,17}$ careful control experiments had to be carried out. $\left[\mathrm{P}\left(\mathrm{C}_{6} \mathrm{H}_{5}\right)_{3}\right]_{2} \mathrm{PtO}_{2}\left(\sim 10^{-3} \mathrm{M}\right)$ was irradiated $\left(\lambda_{\mathrm{irr}}=313 \mathrm{~nm}\right)$ in the presence of DIF $(\sim 4.5 \times$ $10^{-5} \mathrm{M}$ ) in a deaerated solution of $\mathrm{CHCl}_{3}$. More than $70 \%$ of the incident light was absorbed by the platinum complex. The photolysis was accompanied by a rapid decrease of the absorption maximum at $420 \mathrm{~nm}$, indicating the disappearance of DIF. When DIF was irradiated under identical conditions in aerated or deaerated solutions of $\mathrm{CHCl}_{3}$ in the absence of the complex, only a very slow decrease of the absorption maximum at $420 \mathrm{~nm}$ was observed.

In dioxygen complexes of transitions metais electron density is generally shifted from the metal to the dioxygen ligand. ${ }^{19}$ This was confirmed by calculations for $\left(\mathrm{PH}_{3}\right)_{2} \mathrm{PtO}_{2}$ which was used as a model for $\left[\mathrm{P}\left(\mathrm{C}_{6} \mathrm{H}_{5}\right)_{3}\right]_{2} \mathrm{PtO}_{2} \cdot{ }^{20}$ Since the photolysis was accomplished by light absorption into the long-wavelength $\mathrm{ab}$ -

(11) Sostero, S.; Traverso, O.; Lenarda, M.; Graziani, M. J. Organomet. Chem. 1977, 134, 259.

(12) Vogler, A.; Wright, R. E.; Kunkely, H. Angew. Chem. Int. Ed. Engl. $1980,19,717$.

(13) (a) Lion, Y.; Delmelle, M.; Van de Vorst, A. Nature (London) 1976, 263, 442. (b) Cannistraro, S.: Van de Vorst, A. Biochem. Biophys. Res. Commun. 1977, 74, 1177. (c) Cannistraro, S.; Jori, G.; Van de Vorst; A. Photochem. Photobiol. 1978, 28, 257. (d) Maillard, P.; Krausz, P.; Giannotti, C.; Gaspard, S. J. Organomet. Chem. 1980, 197, 285. (e) Ivanov, V. B.; Shlyapintokh, V. Y.; Khvostach, O. M.; Shapiro, A. B.; Rozantsev, E. G. J. Photochem. 1975, 4, 313.

(14) Bellus, D. "Singlet Oxygen"; Ranby, B., Rabeck, J. F., Eds.; Wiley: New York, 1978; Chapter 9.

(15) Bellus, D.; Lind, H.; Wyatt, J. F. J. Chem. Soc., Chem. Commun. 1972, 1199

(16) Dabco does not absorb above $300 \mathrm{~nm}$; see ref 14.

(17) Bell, J. A.; MacGillivray, J. D. J. Chem. Educ. 1974, 51, 677.

(18) Merkel, P. B.; Kearns, D. R. J. Am. Chem. Soc. 1975, 97, 462.

(19) Vaska, L. Acc. Chem. Res. 1976, 9, 175.

(20) Norman, J. G. J. Am. Chem. Soc. 1974, 96, 3327. 
sorption of this complex the lowest energy excited state may initiate the photodissociation. The calculation shows that the lowest energy transition $\left(7 a_{2} \rightarrow 19 b_{2}\right)$ is essentially an intraligand $\left(\mathrm{O}_{2}\right)$ transition with a ligand-to-metal $\left(\mathrm{O}_{2} \rightarrow \mathrm{Pt}\right)$ charge-transfer contribution. ${ }^{20}$ Consequently, this transition terminates in an excited state with an electronic structure which may be directly related to observed photorelease of electronically excited $\mathrm{O}_{2}$. Indeed, the $7 \mathrm{a}_{2} \rightarrow 19 \mathrm{~b}_{2}$ excitation leaves the $\mathrm{O}_{2}$ ligand almost as neutral as uncoordinated $\mathrm{O}_{2}$ itself, and the excitation energy resides to a large extent at the $\mathrm{O}_{2}$ ligand.

The observation that the irradiation of $\left[\operatorname{Ir}\left(\text { diphos) }{ }_{2} \mathrm{O}_{2}\right]^{+}\right.$leads also to the release of $\mathrm{O}_{2}$ but in its triplet ground state may be related to the different nature of the reactive excited state. It was suggested that a metal-to-ligand ( $\mathrm{Ir} \rightarrow$ diphos) charge-transfer state initiates the photodissociation of the iridium complex. ${ }^{9}$ In the case of the cobalt complex mentioned above, the photoactive absorption band ${ }^{8}$ was assigned to a ligand-to-metal $\left(\mathrm{O}_{2} \rightarrow \mathrm{Co}\right)$ charge-transfer transition., Also this excitation type is different from that of $\left[\mathrm{P}\left(\mathrm{C}_{6} \mathrm{H}_{5}\right)_{3}\right]_{2} \mathrm{PtO}_{2}$. In addition, a comparison between the cobalt and platinum complex seems to be less appropriate due to the different structural features and the bonding modes of $\mathrm{O}_{2}$ in both complexes.

Acknowledgment. Financial support for this research by the Deutsche Forschungsgemeinschaft and the Fonds der Chemischen Industrie is gratefully acknowledged.

(21) Miskowski, V. M.; Robbins, J. L.; Treitel, I. M.; Gray, H. B. Inorg. Chem. 1975, 14, 2318 .

\section{Structures of the $\mathrm{C}_{2} \mathrm{H}_{4} \mathrm{O}^{+}$. Gas-Phase Isomers. Evidence for the Formation of the $\mathrm{CH}_{2} \mathrm{OCH}_{2}{ }^{+} \cdot$ Ion from Ethylene Carbonate}

\author{
Bruno C. Baumann and John K. MacLeod*
}

Research School of Chemistry Australian National University Canberra, A.C.T. 2600, Australia

Received April 29, 1981

A recent $a b$ initio theoretical study ${ }^{1}$ of the structures and stabilities of $11 \mathrm{C}_{2} \mathrm{H}_{4} \mathrm{O}^{+}$. isomers has shown that the ethylene oxide ion 1 is less stable than its $\mathrm{C}$... $\mathrm{C}$ ring-opened isomer 2 , in agreement with measured $\Delta H_{\mathrm{f}}$ values, ${ }^{2}$ but more stable than the isomer 3 resulting from $\mathrm{C} \cdots \mathrm{O}$ bond cleavage (Figure 1). In accord with these results we have found ${ }^{3}$ that ionized ethylene oxide (1) ring-opens to 2 rather than 3 . Kumakura, ${ }^{4}$ however, has proposed 3 to be the reactive species in ion/molecule reactions of the ethylene oxide ion. We now report experimental evidence which confirms that, as suggested by theory, the $\mathrm{C}$... O ring-opened isomer 3 , if formed, is not stable but rapidly isomerizes to 2 .

As a suitable precursor for isomer 3 we chose 1,3-dioxolan-2-one (ethylene carbonate) which after ionization ( 4 unlabeled in Scheme I) readily loses carbon dioxide to give an $\mathrm{m} / z$ 44 ion $\left(\mathrm{C}_{2} \mathrm{H}_{4} \mathrm{O}^{+}\right.$.). ${ }^{5}$ In the ICR spectrometer ${ }^{6}$ this fragment ion showed the $\mathrm{CH}_{2}{ }^{+}$. transfer to neutral pyridine and nitriles typical of isomer $2 .^{3}$ This

(1) Bouma, W. J.; MacLeod, J. K.; Radom, L. J. Am. Chem. Soc. 1979 $101,5540-5545$

(2) Holmes, J. L.; Terlouw, J. K.; Lossing, F. P. J. Phys. Chem. 1976, 80, 2860-2862.

(3) Bouma, W. J.; MacLeod, J. K.; Radom, L. J. Chem. Soc., Chem. Commun. 1978, 724-725.

(4) Kumakura, M.; Arakawa, K.; Sugiura, T. Int. J. Mass Spectrom. Ion Phys. 1978, 26, 303-320. Bull. Chem. Soc. Jpn. 1978, 51, 54-57.

(5) Brown, P. Djerassi, C. Tetrahedron 1968, 24, 2949-2967.

(6) For general conditions of ICR experiments, see: Bouma, W. J.; Ma cLeod, J. K.; Radom, L. J. Am. Chem. Soc. 1980, 102, 2246-2252.

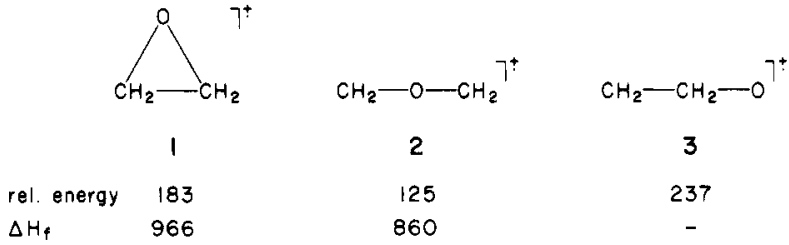

Figure 1. Calculated energies ${ }^{1}$ (relative to the most stable isomer $\mathrm{CH}_{2}=\mathrm{CH}-\mathrm{OH}^{+}$.) and heats of formation ${ }^{2}$ (where measured) in $\mathbf{k J}$ $\mathrm{mol}^{-1}$ of three $\mathrm{C}_{2} \mathrm{H}_{4} \mathrm{O}^{+}$. isomers.

Scheme I

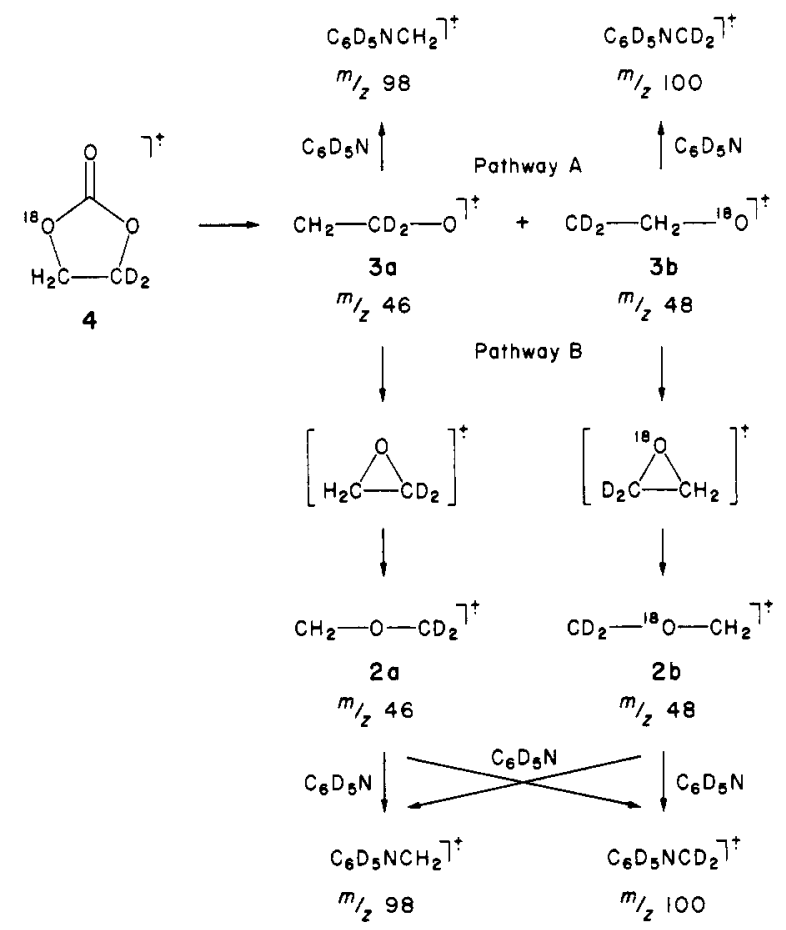

Scheme II

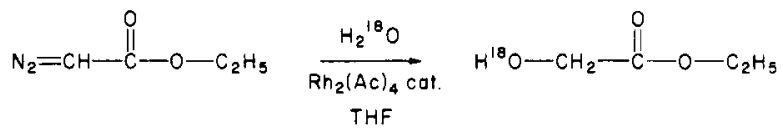

$$
\begin{aligned}
& \text { 望 } \\
& \frac{\mathrm{COCl}_{2}}{\mathrm{CCl}_{4}} \quad \mathrm{H}^{18} \mathrm{O}-\mathrm{CH}_{2}-\mathrm{CD}_{2}-\mathrm{OH}
\end{aligned}
$$

observation, however, did not in itself prove that isomer 3, if formed initially, had rearranged to 2 before reacting with a neutral substrate since 3 could equally well be expected to transfer $\mathrm{CH}_{2}{ }^{+}$. with concomitant formation of neutral formaldehyde.

In order to determine whether the $\mathrm{m} / \mathrm{z} 44$ ion which was responsible for $\mathrm{CH}_{2}^{+} \cdot$ transfer had the structure 2 or 3 , we prepared (see below) $1,3-\left[1-{ }^{18} \mathrm{O}, 4,4-{ }^{2} \mathrm{H}_{2}\right]$ dioxolan-2-one as a precursor. Its molecular ion 4 (Scheme I) can lose either $\mathrm{CO}^{18} \mathrm{O}$ or $\mathrm{CO}_{2}$ to give two primary fragment ions $3 \mathbf{a}(m / z 46)$ and $3 \mathbf{b}(m / z 48)$, respectively. On transfer of a methylene radical cation ${ }^{7}$ to pyridine- $d_{5},{ }^{8}$ 3a would give rise to the product ion $\mathrm{m} / z$ 98 exclusively, while 3b would be the only precursor for $m / z 100$ (pathway A). Alternatively, isomerization of $\mathbf{3 a}$ and $\mathbf{3 b}$ to $\mathbf{2 a}$ and $\mathbf{2 b}$, respectively (pathway B), ${ }^{9}$ and subsequent methylene transfer to pyridine- $d_{5}$,

(7) The ICR experiments have shown that no H/D scrambling occurs. (8) In the experiments with the labeled ethylene carbonate, pyridine- $d_{5}$ was used as a neutral substrate in order to avoid overlapping of the product ion peaks with other more intense peaks in the ICR spectrum. 